\title{
Histological Pattern of Gynecological Cancers
}

\author{
Dhakal HP, ${ }^{1}$ Pradhan $M^{1}$ \\ 'Department of Pathology, BP Koirala Memorial Cancer Hospital, Bharatpur, Chitwan, Nepal.
}

\section{ABSTRACT}

Introduction: The information on cancer incidence is an important basis to prioritize the preventive policy of a country. Since there are only limited reports on the gynecological cancers in Nepal, the present study was undertaken to further elucidate the incidences of different gynecological cancers by age, site and histological subtype in a large series.

Methods: A retrospective analysis was performed in histopathologically proven gynecological malignancies by retrieving data from the archives of the Department of Pathology, BP Koirala Memorial Cancer Hospital between July 1999 and April 2004.

Results: Out of total 1517 cases of gynecological cancers diagnosed, 1293 cases (85.23\%) were cervical, $97(6.39 \%)$ ovarian, $48(3.16 \%)$ vulval, $41(2.7 \%)$ vaginal, $32(2.11 \%)$ endometrial cancers as well as 5 $(0.33 \%)$ choriocarcinoma and $1(0.07 \%)$ fallopian tube cancer. Squamous cell carcinoma was the commonest histologic type in cervical, vaginal and vulval cancers whereas serous adenocarcinoma and endometrioid adenocarcinoma were commonest histological types in the ovary and endometrium respectively. Gynecological cancers were most common in age between 40 and 60 years with mean age 45 years.

Conclusions: Cervical cancer is the most frequent gynecological malignancy in Nepal. Since it is a preventable disease, national screening and awareness programs are necessary to reduce the burden of the cancer and to improve the health of women in Nepal.

Key Words: cancer, cervix, endometrium, ovary, vagina, vulva

\section{INTRODUCTION}

Gynecological cancer is a public health problem worldwide. ${ }^{1}$ However, the incidences of different gynecological malignancies vary geographically. In the western countries, endometrial cancer is more prevalent whereas cervical cancer is most frequent in the developing countries. ${ }^{2}$

Correspondence:
Dr. Hari Prasad Dhakal
Department of Pathology
The Norwegian Radium Hospital
Oslo University Hospital
Montebello, 0310 Oslo, Norway.
Email: aastha2@yahoo.com
Phone: 4722934277


In Nepal, only few reports have been published in small cohorts of patients. ${ }^{3-7}$ Gynecological cancer is the most frequent cancer among patients visiting BP Koirala Memorial Cancer Hospital, Bharatpur, the Nepalese national cancer hospital, according to its annual report. ${ }^{8}$ We have analyzed a large series of gynecological malignancies from national cancer center for a period of four years and ten months to elucidate the incidences of different gynecological cancers by age, site and histological subtype.

\section{METHODS}

This is a retrospective descriptive analysis of all patients with gynecological cancer who underwent histopathological examination in Department of Pathology, BP Koirala Memorial Cancer Hospital between July 1999 and April 2004. We have published initial part of this series comprising 321 gynecological cancer cases earlier. ${ }^{7}$ Here, as an extended study of the series in a large number of patients constituting 1517 (which includes the 321 cases published earlier ${ }^{7}$ ), malignant neoplasms from female genital system namely vulva, vagina, uterine cervix, corpus uteri, ovary, and fallopian tube have been analyzed for distribution by age, site and histologic type. The permission to use the data for this study was obtained from the institute.

All relevant data on histopathologically proven malignant cases were retrieved from the archives of the Department of Pathology, BPKMCH. The histological diagnoses had been made following the recommendation of WHO classification system. $^{9}$

The descriptive analyses were performed using Excel software program for windows by Microsoft.

\section{RESULTS}

\section{Cervical cancer}

Cancer of cervix (1293 cases) was found to be the commonest gynecological malignancy (Table 1). Twenty seven cases of carcinoma in situ were also diagnosed during this period. Ninety-four percent (1212 cases) were squamous cell carcinoma (Table 2) and its peak incidence was between 40 and 49 years followed by $50-59$ years (Table 3 ). The mean age of the invasive squamous cell carcinoma, in situ carcinoma and adenocarcinoma were 49.6 years, 44.9 years, and 49.9 years respectively. The invasive and in situ squamous cell carcinomas were rare below the age of 30 years (Table 3 ). Adenocarcinoma constituted $3.45 \%$ (45 cases) and other histologic types were less than $1 \%$.

Table 1. Distribution of gynecological cancer

\begin{tabular}{lll}
\hline Site & No. & $(\%)$ \\
\hline Cervical cancer & 1293 & $(85.2$ \\
Ovarian cancer & 97 & $(6.4)$ \\
Vulval cancer & 48 & $(3.2)$ \\
Vaginal cancer & 41 & $(2.7)$ \\
Cancer of corpus uteri & 37 & $(2.4)$ \\
Fallopian tube cancer & 1 & $(0.1)$ \\
Total & 1517 & $(100)$ \\
\hline
\end{tabular}

Table 2. Histopathological pattern of cervical, vulval and vaginal cancer

\begin{tabular}{|c|c|c|c|c|c|c|}
\hline \multirow{2}{*}{$\begin{array}{l}\text { Histopathological } \\
\text { Type }\end{array}$} & \multicolumn{2}{|c|}{ Cervical cancer } & \multicolumn{2}{|c|}{ Vulval cancer } & \multicolumn{2}{|c|}{ Vaginal Cancer } \\
\hline & No. & $(\%)$ & No. & $10 \%$ & No. & $\%$ \\
\hline Squamous cell Carcinoma & 1212 & (93.7) & 47 & (97.9) & 33 & $(80.5)$ \\
\hline Adenocarcinoma & 45 & (3.8) & 1 & (2.1) & 4 & (9.8) \\
\hline Squamous cell carcinoma in situ & 27 & (2.1) & - & - & 1 & (2.4) \\
\hline Small cell carcinoma & 4 & (0.3) & - & - & - & - \\
\hline Adenosquamous carcinoma & 3 & $(0.2)$ & - & - & - & - \\
\hline Carcinosarcoma & 2 & $(0.2)$ & - & - & - & - \\
\hline Rhabdomyosarcoma & - & . & - & - & 1 & $(2.4)$ \\
\hline Malignant melanoma & - & - & - & - & 2 & (4.9) \\
\hline Total & 1293 & $(100)$ & 48 & $(100)$ & 41 & $(100)$ \\
\hline
\end{tabular}

Table 3. Age distribution of invasive, in situ squamous cell carcinoma and adenocarcinoma of the uterine cervix

\begin{tabular}{|c|c|c|c|c|c|c|}
\hline \multirow[b]{2}{*}{ Age group } & \multirow{2}{*}{\multicolumn{2}{|c|}{$\begin{array}{l}\text { Invasive Squamous cell carcinoma } \\
\text { No. }(\%)\end{array}$}} & \multicolumn{2}{|c|}{ In situ squamous cell carcinoma } & \multicolumn{2}{|c|}{ Adenocarcinoma } \\
\hline & & & No. & & No. & \\
\hline $20-29$ & 26 & $(2.2)$ & - & - & 1 & $(2.2)$ \\
\hline $30-39$ & 194 & $(16.0)$ & 13 & $(48.2)$ & 5 & $(11.1)$ \\
\hline $40-49$ & 433 & (35.7) & 3 & $(11.1)$ & 17 & $(37.8)$ \\
\hline $50-59$ & 324 & (26.7) & 8 & $(29.6)$ & 16 & (35.6) \\
\hline $60-69$ & 179 & $(14.8)$ & 3 & $(11.1)$ & 3 & $(6.7)$ \\
\hline $70-79$ & 48 & $(4.0)$ & - & - & 3 & (6.7) \\
\hline $80-89$ & 8 & $(0.67)$ & - & - & - & - \\
\hline Total & 1212 & $(100)$ & 27 & $(100)$ & 45 & $(100)$ \\
\hline Mean age (years) & 49.6 & & 44.9 & & 49. & \\
\hline
\end{tabular}


Dhakal et al. Histological Pattern of Gynecological Cancers

\section{Ovarian cancer}

Ovarian cancers (97 cases) were the second most common gynecological malignancy (Table 1) with serous adenocarcinoma being the commonest histologic type followed by mucinous adenocarcinoma (Table 4). Cases of Kurkenberg's tumour were also observed along with few other histologic types of epithelial, stromal and germ cell origin. The commonest affected age group was between 40 and 49 years with mean age 44.71 years (Table 5).

Table 4. Histopathological pattern of ovarian cancer

\begin{tabular}{lll}
\hline Histopathological Type & No. & (\%) \\
\hline Serous adenocarcinoma & 59 & $(60.8)$ \\
Mucinous adenocarcinoma & 9 & $(9.3)$ \\
Krukenberg's tumour & 5 & $(5.2)$ \\
Endometrioid adenocarcinoma & 5 & $(5.2)$ \\
Borderline serous tumor & 2 & $(2.1)$ \\
Immature teratoma & 3 & $(3.1)$ \\
Mixed germ cell tumour & 2 & $(2.1)$ \\
Granulosa cell tumour & 6 & $(6.2)$ \\
Small cell carcinoma & 1 & $(1.0)$ \\
Dysgerminoma & 3 & $(3.1)$ \\
Yolk sac tumour & 2 & $(2.1)$ \\
Total & 97 & $(100)$ \\
\hline
\end{tabular}

Table 5. Age distribution of vulval, vaginal, ovarian and endometrial cancer.

\begin{tabular}{lllllllll}
\hline \multicolumn{3}{r}{ Vulval cancer } & \multicolumn{3}{c}{ Vaginal cancer } & \multicolumn{3}{c}{ Ovarian cancer Endometrial cancer } \\
\multicolumn{1}{l}{ Age group No. } & $\%$ & No. & $\%$ & No. & $\%$ & No. & $\%$ \\
\hline $10-19$ & - & - & - & - & 7 & $(7.2)$ & - & - \\
$20-30$ & 1 & $(2.1)$ & 3 & $(7.3)$ & 7 & $(7.2)$ & - & - \\
$30-39$ & 1 & $(2.1)$ & 2 & $(4.9)$ & 9 & $(9.3)$ & 1 & $(3.1)$ \\
$40-49$ & 14 & $(29.2)$ & 7 & $(17.1)$ & 35 & $(36.1)$ & 3 & $(9.4)$ \\
$50-59$ & 15 & $(31.3)$ & 17 & $(41.5)$ & 33 & $(34.0)$ & 18 & $(56.3)$ \\
$60-69$ & 10 & $(20.8)$ & 10 & $(24.4)$ & 5 & $(5.2)$ & 8 & $(25)$ \\
$70-79$ & 6 & $(12.5)$ & 2 & $(4.9)$ & 1 & $(1.0)$ & 2 & $(6.3)$ \\
$80-89$ & 1 & $(2.1)$ & - & - & - & - & - & - \\
Total & 48 & $(100)$ & 41 & $(100)$ & 97 & $(100)$ & 32 & $(100)$ \\
Mean age (years) & 55.9 & & 53.4 & & 44.7 & & 56.7
\end{tabular}

\section{Vulval and vaginal cancer}

Altogether 48 vulval and 41 vaginal cancers were reported during the period. Squamous cell carcinoma was the commonest histologic type (Table 2) and the peak incidence was observed between 50 and 59 years for both sites (Table 5). The mean age for vulval and vaginal cancers was 55.9 years and 53.4 years respectively.

\section{Cancer of corpus uteri}

Of 32 cases of endometrial cancers, 26 (81.3\%) were endometrioid adenocarcinoma, five $(15.6 \%)$ were stromal sarcoma and one $(3.1 \%)$ squamous cell carcinoma. The mean age of the patient was 56.7 years (Table 5 ). In addition, five cases of choriocarcinoma were also documented.

\section{Cancer of fallopian tube}

One case of fallopian tube carcinoma was also found during the period.

\section{DISCUSSION}

In present series, we have observed a high incidence of carcinoma of cervix in Nepalese women and this further confirms the findings of smaller series reported earlier. ${ }^{4-7}$ This observation is also in line with what is seen in some of the African countries, Latin America and the Caribbean, south-central Asia and southeast Asia. ${ }^{1}$ However, cancer cervix incidence varies with geographical region and ethnicity. ${ }^{10}$ In this study, squamous cell carcinoma was the most common histologic subtype and it constituted $95 \%$ of all cervical cancers which is a bit higher compared to earlier reports. ${ }^{9,11}$ Though we observed predominantly squamous cell carcinoma with only small percentage of adenocarcinoma in Nepal, the incidence of adenocarcinoma is increasing in the western population. ${ }^{9,12,13}$

Various factors have been implicated for the high incidence of cancer cervix, importantly, sexually transmitted human papilloma virus (HPV) infection. Risk factors for HPV infection are multiple sex partners, partner's multiple partners, high parity, smoking, poor hygiene, absence of male circumcision, and immunodeficiency states e.g. HIV infection. ${ }^{9}$ In Nepalese context, one or several of above mentioned risk factors might be the cause for the high incidence of cervical cancer. There are no data on the prevalence of HPV infection in the general population or on the prevalence of different HPV types in cervical cancer and cervical intraepithelial neoplasia cases in Nepal. ${ }^{14}$ In the general population of neighboring countries of Nepal, the prevalence of high-risk HPV infection varied from $7-13 \%$ and high-risk HPV types were found in $98 \%$ of cervical cancers. ${ }^{14}$ The declining incidence of 
squamous cell carcinoma in the developed countries is attributed to preventive measures like effective screening program and decreased parity as well as better living conditions whereas it is still the commonest cancer among women in the developing countries. ${ }^{9}$ The screening for precursor lesions of cervical cancer has started in Nepal only in few urban areas; there is no regular screening or awareness program for the prevention at a national level for women of risk age group. It has been suggested that no more than 20,000 smears are examined annually in the country with approximately 14 million female population, ${ }^{14}$ making it grossly inadequate. Therefore, the observation of such a high number of preventable and, if diagnosed in the early stage, potentially curable cancer among Nepalese women points out an urgent need for effective preventive measures including screening and awareness programs.

Ovarian cancer is the sixth most common cancer among women in the world with slowly increasing incidence in developed countries. ${ }^{1}$ The cancer accounts $30 \%$ of all malignant neoplasms in female genital organs and is more common in developed countries than in developing countries. High parity and the use of oral contraceptives have shown to reduce the risk of developing ovarian cancer whereas obesity is associated with the increased risk. ${ }^{9}$ In this study, ovarian cancer was the second most frequent malignancy in the female genital system constituting about $6 \%$ of total gynecological cancers which is much less than what is reported in other countries including western countries. ${ }^{9}$ Serous adenocarcinoma is the most common histologic type in this series followed by mucinous adenocarcinoma, the finding is in concordance with a report from Kathmandu. ${ }^{15}$ It is important to assess ovarian cancer histologically as serous adenocarcinoma is reported to be linked to family history of ovarian or breast cancer. ${ }^{9,16}$ Smoking has been found to be associated with mucinous adenocarcinoma. ${ }^{17}$ Histologic sub-typing is necessary for the treatment decision as germ cell tumors are potentially curable at all stages ${ }^{18,19}$ and for prognostication. ${ }^{20}$ Serous and undifferentiated carcinomas have worse prognosis compared to other carcinomas. ${ }^{20}$

We observed a low incidence of endometrial cancer in our study with only 32 cases, $2 \%$ of all gynecological cancers. The cases were mainly endometrioid adenocarcinoma and not a single case of serous adenocarcinoma or clear cell carcinoma. This is in contrast to what is reported in western countries where it is the most common cancer of female genital system with $35 \%$ of all gynecological cancers. ${ }^{9}$ Since low parity is a risk factor for endometrioid adenocarcinoma, ${ }^{9}$ the observed low incidence of endometrioid carcinoma in Nepalese women might be due to high parity. However, this hypothesis needs to be investigated epidemiologically. Endometrial cancer is a disease of postmenopausal age predominantly occurring in women with mean age of 57 years similar to an earlier report. ${ }^{1}$ The long term use of tamoxifen has increased the risk for endometrial cancer. ${ }^{9}$ As there is no information available at present, it is assumed that the number of surviving breast cancer patients under Tamoxifen therapy is increasing in Nepal. This points out the need of regular and careful evaluation of endometrium of such women for early diagnosis and potential cure.

In the present study, squamous cell carcinoma is the commonest histologic type in vagina similar to published reports. ${ }^{9,21}$ The etiology of the cancer is similar to cervical carcinoma and is associated with HPV infection.

In vulva, squamous cell carcinoma is the most common histological type ${ }^{9,22}$, and the cancer is related to persistent HPV infection. ${ }^{9}$ In vulval cancer, age is an important factor; the patients older than 50 years have worse prognosis than patients younger than 50 years. ${ }^{23}$ In our series, the peak incidence was observed between 50 59 years with decline in the incidence afterwards whereas, in the United States, the incidence is higher after 65 years of age and consistently increasing thereafter. ${ }^{22}$ As both vaginal and vulval carcinomas are associated with HPV infection, awareness program regarding the risk factors can play a vital role in preventing the occurrence of these cancers.

\section{CONCLUSIONS}

In this study, we have confirmed the high incidence of preventable cancers in Nepalese context especially cancer cervix, vulva and vagina. Histologically, squamous cell carcinoma is the commonest. Since cancer of cervix is a serious health problem among Nepalese women, effective national screening and awareness programs should be established in order to reduce the burden of the disease and to improve the health of women in Nepal. 


\section{REFERENCES}

1. Parkin DM, Bray F, Ferlay J, Pisani P. Global cancer statistics, 2002. CA Cancer J Clin. 2005;55(2):74-108.

2. Stewart BW, Kleihues P, editors. World Cancer Report. Lyon: World health organization, International Agency for Research on Cancer; 2003.

3. Binu VS, Chandrashekhar TS, Subba SH, Jacob S, Kakria A, Gangadharan P, et al. Cancer pattern in Western Nepal: a hospital based retrospective study. Asian Pac J Cancer Prev. 2007;8(2):183-6.

4. Dhakal HP. An experience in DCC BP Koirala Memorial Cancer Hospital. BPKMCH Newsletter. 1998;18-20.

5. Mohammad A, Makaju R. Retrospective histopathological analysis of various neoplasms of the female reproductive system (FRS) seen at the Kathmandu University Teaching Hospital, (KUTH) Dhulikhel, Nepal. Kathmandu Univ Med J (KUMJ). 2006;4(1):48-53.

6. Pradhan M, Adhikari R, Joshi A, Sigdel B, Basnet RB, Amatya VJ, et al. Present cancer status in T.U. Teaching Hospital. Journal of Society of Surgeons of Nepal. 1999;2(2):13-23.

7. Pradhan M, Dhakal HP, Pun CB, Pradhan S, Dangal G. Gynecological malignancy in $\mathrm{BPKMCH}$, Bharatpur: A retrospective analysis of 321 cases. JNMA J Nepal Med Assoc. 2001;40:108-11.

8. BP Koirala Memorial Cancer Hospital. Annual report 2004. Bharatpur,Nepal: BPKMCH; 2008.

9. Tavassoli FA, Devilee P, editors. Pathology and Genetics: tumours of the breast and female genital organs. Lyon: World health organization, International Agency for Research on Cancer; 2003.

10. Rastogi T, Devesa S, Mangtani P, Mathew A, Cooper N, Kao $\mathrm{R}$, et al. Cancer incidence rates among South Asians in four geographic regions: India, Singapore, UK and US. Int J Epidemiol. 2008;37(1):147-60.

11. Watson M, Saraiya M, Benard V, Coughlin SS, Flowers L, Cokkinides V, et al. Burden of cervical cancer in the United States, 1998-2003. Cancer. 2008;113(10 Suppl):2855-64.

12. Vesterinen E, Forss M, Nieminen U. Increase of cervical adenocarcinoma: a report of 520 cases of cervical carcinoma including 112 tumors with glandular elements. Gynecol Oncol. 1989;33(1):49-53.
13. Alfsen GC, Thoresen SO, Kristensen GB, Skovlund E, Abeler VM. Histopathologic subtyping of cervical adenocarcinoma reveals increasing incidence rates of endometrioid tumors in all age groups: a population based study with review of all nonsquamous cervical carcinomas in Norway from 1966 to 1970, 1976 to 1980, and 1986 to 1990. Cancer. 2000;89(6):12919.

14. Sankaranarayanan R, Bhatla N, Gravitt PE, Basu P, Esmy PO, Ashrafunnessa KS, et al. Human papilloma virus infection and cervical cancer prevention in India, Bangladesh, Sri Lanka and Nepal. Vaccine. 2008;26(Suppl 12):M43-M52.

15. Jha R, Karki S. Histological pattern of ovarian tumors and their age distribution. Nepal Med Coll J. 2008;10(2):81-5.

16. Chiaffarino F, Parazzini F, Bosetti C, Franceschi S, Talamini $\mathrm{R}$, Canzonieri V, et al. Risk factors for ovarian cancer histotypes. Eur J Cancer. 2007;43(7):1208-13.

17. Kurian AW, Balise RR, McGuire V, Whittemore AS. Histologic types of epithelial ovarian cancer: have they different risk factors? Gynecol Oncol. 2005;96(2):520-30.

18. Culine S, Lhomme C, Kattan J, Duvillard P, Michel G, Gerbaulet A, et al. Cisplatin-based chemotherapy in dysgerminoma of the ovary: thirteen-year experience at the Institut Gustave Roussy. Gynecol Oncol. 1995;58(3):344-8.

19. Pectasides D, Pectasides E, Kassanos D. Germ cell tumors of the ovary. Cancer Treat Rev. 2008;34(5):427-41.

20. Heintz AP, Odicino F, Maisonneuve P, Beller U, Benedet JL, Creasman WT, et al. Carcinoma of the ovary. Int J Gynaecol Obstet. 2003;83(Suppl 1):135-66.

21. Wu X, Matanoski G, Chen VW, Saraiya M, Coughlin SS, King $\mathrm{JB}$, et al. Descriptive epidemiology of vaginal cancer incidence and survival by race, ethnicity, and age in the United States. Cancer. 2008;113(10 Suppl):2873-82.

22. Saraiya M, Watson M, Wu X, King JB, Chen VW, Smith JS, et al. Incidence of in situ and invasive vulvar cancer in the US, 1998-2003. Cancer. 2008;113(10 Suppl):2865-72.

23. Pingley S, Shrivastava SK, Sarin R, Agarwal JP, Laskar S, Deshpande DD, et al. Primary carcinoma of the vagina: Tata Memorial Hospital experience. Int J Radiat Oncol Biol Phys. 2000;46(1):101-8.

24. Kumar S, Shah JP, Bryant CS, Imudia AN, Morris RT, Malone $\mathrm{JM}$, Jr. A comparison of younger vs older women with vulvar cancer in the United States. Am J Obstet Gynecol. 2009 May;200(5):e52-5. 